\title{
Mating in the rhesus monkey (Macaca mulatta) after conception and its relationship to oestradiol and progesterone levels throughout pregnancy
}

\author{
C. Bielert,* J. A. Czaja, S. Eisele, G. Scheffler, J. A. Robinson \\ and R. W. Goy \\ Wisconsin Regional Primate Research Center, and Department of Psychology, \\ University of Wisconsin, Madison, Wisconsin 53706, U.S.A.
}

\begin{abstract}
Summary. Behavioural and hormonal data were collected throughout pregnancy in captive rhesus monkeys. Heterosexual pairs observed in daily time-limited mating tests showed two distinct periods of increased sexual interaction, as measured by the incidence of ejaculation. One period was coincident with the preovulatory oestradiol peak, while the other occurred between the 6th and 10th weeks of pregnancy. The positive relationship found during the menstrual cycle between the ratio of circulating oestradiol:progesterone and degree of sexual activity continued for the first 8 weeks of pregnancy. However, sexual activity ceased in the second half of pregnancy despite a continued high oestradiol:progesterone ratio.
\end{abstract}

\section{Introduction}

Mating in most mammals is limited to a relatively distinct periovulatory period (Young, 1961; Lisk, 1973), but man and some Old World primates continue to copulate through much or all of the menstrual cycle and during pregnancy (Homo sapiens: Masters \& Johnson, 1966; Udry \& Morris, 1968; Falicov, 1973; Kenny, 1973; Gorilla gorilla: Hess, 1973; Pan troglodytes: van Lawick-Goodall, 1969; Macaca nemestrina: Eaton \& Resko, 1974; Macaca fuscata: Hanby et al., 1971; Macaca mulatta: Michael \& Herbert, 1963; Conaway \& Koford, 1964; Loy, 1971). Ovarian hormones are not without influence in these primates, however, since cyclic changes in certain sexual behaviour patterns have been related to stages of the menstrual cycle under natural (Carpenter, 1942; Kaufmann, 1965; Lindberg, 1971; Loy, 1971) and laboratory (Ball \& Hartman, 1935; Evans \& Goy, 1968; Scruton \& Herbert, 1970; Goldfoot, 1971; Bullock et al., 1972; Eaton et al., 1973; Czaja \& Bielert, 1975) conditions.

Studies relating endogenous hormone levels to mating behaviour in the laboratory, where pregnancy can be easily prevented without disrupting endocrine function, have concentrated on menstrual cycles in which pregnancy does not occur (Goy \& Resko, 1972; Eaton \& Resko, 1974). This is not, however, the normal reproductive state of wild animals. Suppression of ovulation during the prolonged periods of primate pregnancy and lactation or during periods of seasonal amenorrhoea means that the reproductive life of free-ranging primate females consists mainly of conditions of infertility.

It is often assumed that the apparent biological dissociation represented by the continued mating of primates during non-fertile states reflects behavioural independence from hormonal action and/or overriding social influences (Rowell, 1972). While it is now accepted that the periovulatory steroid changes in primates can increase sexual activity, the question remains as to whether hormonal variations at other times influence the display of mating activity. Since endocrine changes during pregnancy naturally induce elevated steroid levels, a study was undertaken to document the incidence of sexual behaviour and concomitant levels of circulating oestradiol and progesterone in captive rhesus monkeys throughout this period.

\footnotetext{
* Present address: Primate Behaviour Unit, The University of Witwatersrand, Johannesburg, South Africa.
} 


\section{Materials and Methods}

Fourteen wild-caught rhesus monkeys which had been in the laboratory for at least 2 years were used. The eight females and six males were all proven breeders and were members of the Wisconsin Regional Primate Research Center Breeding Colony.

Sexual skin colour. As indicators of ovarian condition, daily records of menstruation and sex skin colour were maintained. The intensity of colour of the female perineal (sex) skin was arbitrarily scored on a quarter-step scale with a minimum of 0.00 and a maximum of 4.25 as previously described (Czaja et al., 1975). Although the degree of skin colour fluctuation varies among individual rhesus females, systematic changes in relative colour intensity have been reported to occur during ovulatory cycles (Hartman, 1932; Czaja et al., 1975) and following administration of gonadal hormones (Allen, 1927).

Steroid assays. Blood samples $(2.5 \mathrm{ml})$ were taken from saphenous veins of six females at $1-2$ day intervals during the 2 weeks about the expected time of ovulation and at intervals of 2-4 days throughout pregnancy until the week after parturition.

Concentrations of oestradiol-17 $\beta$ and progesterone were measured by the radioimmunoassays previously described (Hotchkiss et al., 1971 ; Resko, 1971 ; Resko et al., 1974). For oestradiol measurements, serum volumes of $0.05-0.5 \mathrm{ml}$ were extracted twice with $4.0 \mathrm{ml}$ fresh diethyl ether (A.R., Mallinckrodt). The combined extracts were dried and concentrated under a gentle flow of filtered air. Oestradiol separations were accomplished on 0.8 g Sephadex LH-20 (Pharmacia Fine Chemicals) columns. A methylene chloride: methanol $(98: 2 \mathrm{v} / \mathrm{v})$ solvent system (Nuti et al., 1974) resulted in the following elution pattern: $4.0 \mathrm{ml}$, neutral steroids; $3.0 \mathrm{ml}$, oestrone; $2.0 \mathrm{ml}$, discard; $6.0 \mathrm{ml}$, oestradiol-17 $\beta$.

Recoveries were estimated by the addition of $1000 \mathrm{ct} / \mathrm{min}\left[4,6,7-{ }^{3} \mathrm{H}\right]$ oestradiol- $17 \beta$ (sp. act. $106 \mathrm{Ci} / \mathrm{mmol}$ : New England Nuclear) to the plasma samples before extraction. After column separation, aliquots of the oestradiol fractions were taken for recovery determinations. Good recoveries, $84 \cdot 1 \pm 4 \cdot 13$ (S.D.) $\%$, were consistently obtained. The range of the standard curve was $5-150 \mathrm{pg}$. Blank values were $0.5 \pm 1.41 \mathrm{pg}$, and the sensitivity of the assay was $3.3 \mathrm{pg}$ (Ekins \& Newman, 1970). The within-assay variation, calculated as described by van der Molen (1970), was $\pm 5.99 \mathrm{pg}$ for duplicate determinations on 21 samples containing 10-166 pg oestradiol. Pools of serum from females were assayed in triplicate with each assay to serve as a between-assay control. Values obtained for the two pools were $12 \cdot 6 \pm 1 \cdot 72 \mathrm{pg}$ and $47 \cdot 5 \pm 4 \cdot 16 \mathrm{pg}$. Different volumes of a normal plasma pool were checked for their effect on the radioimmunoassay. Volumes of $0 \cdot 05,0 \cdot 10,0 \cdot 20,0.30$ and $0.50 \mathrm{ml}$ resulted in assay values of $3.8,7 \cdot 2,15 \cdot 6,25.9$, and $40.1 \mathrm{pg}$, respectively. These values are represented by a straight line and have a correlation coefficient of 0.9932 .

Progesterone levels were analysed on separate aliquots of the individual serum samples. Aliquots of $0.025-0.250 \mathrm{ml}$ were extracted twice with $4.0 \mathrm{ml}$ petroleum ether (Mallinckrodt, Nanograde) (Johansson et al., 1968; Johansson, 1969). Before extraction, $1000 \mathrm{ct} / \mathrm{min}\left[1,2,6,7-{ }^{3} \mathrm{H}\right]$ progesterone (sp. act. $96 \mathrm{Ci} / \mathrm{mmol}$ : New England Nuclear) were added to the samples for recovery estimations. Recovery determinations were $90 \cdot 5 \pm 2 \cdot 78 \%$.

The antibody for progesterone was obtained from rabbits immunized with progesterone-11 $\alpha$ succinyl-bovine serum albumin (Resko et al., 1974), an antibody specific for progesterone (Thorneycroft \& Stone, 1972; Resko et al., 1974). The range of the standard curve utilized was 10-500 pg. Values of 7.2 $\pm 2 \cdot 36 \mathrm{pg}$ were obtained for assay blanks, and the sensitivity was found to be $11.9 \mathrm{pg}$. Within-assay variability for 83 duplicate samples from 13 to $509 \mathrm{pg}$ was $\pm 11.69 \mathrm{pg}$. Between-assay variability based on a serum pool assessed in each assay was calculated to be $\pm 26.75 \mathrm{pg}$. Assay values of $11 \cdot 3,43 \cdot 1,135 \cdot 7$ and $508 \cdot 4 \mathrm{pg}$ were obtained from $0 \cdot 01,0 \cdot 05,0 \cdot 10$ and $0 \cdot 25 \mathrm{ml}$ of a serum pool, giving a nearly straight line with a correlation coefficient of 0.9828 .

Behavioural tests. The male and female of a pair were housed in adjoining cages. At the start of a mating test, a panel separating the cages and the pair was removed and interactions in the resulting $90 \times 150 \times 100 \mathrm{~cm}$ cage were scored for a standard 12-min period. At the end of that time, the pair was separated and the partition replaced. Rhesus mating behaviour is characterized by a series of mounts with intromissions ending with the ejaculatory mount (Bielert \& Goy, 1973). Ejaculation is 
easily distinguished, being characterized by a series of deep pelvic thrusts followed immediately by body tenseness, immobility, and slight quivering of the flanks. Although other behaviour was scored, the proportion of tests in which ejaculation occurred was used as the primary index of sexual activity.

Collection and analysis of data. Eight females became pregnant: No. 1089 in March, Nos 55, 68, 1434 and 1506 in June, Nos 1126, 1415 and 1515 in July. Simultaneous data on steroid concentration and behaviour were obtained for Nos 1089, 1126, 1434 and 1506. Monkeys 55 and 68 were bled but not behaviourally tested; Nos 1415 and 1515 were behaviourally tested but not bled.

The day of the preovulatory oestradiol peak was designated Day 0 . In our laboratory, we find that a distinctive decrease from maximum sex skin colour (colour breakdown) occurs an average of 2.5 days after the preovulatory oestradiol peak. For the two females from which blood was not collected, the second day before colour breakdown was designated Day 0. For all females, Day 1 was then arbitrarily defined as the first day of pregnancy, since the LH surge and ovulation generally occur within $48 \mathrm{hr}$ of the preovulatory oestradiol surge (Weick et al., 1973). In computing group averages, the results for the period from 2 weeks before conception until 1 week after parturition were used for all females, except No. 1506, for which only the results until Day 84 were included.

\section{Results}

Measures during early pregnancy were found to show similar changes whether simultaneously or separately collected and the results were subsequently combined for all subjects (Table 1). The average interval between the preovulatory menstrual bleeding and the bleeding occurring after conception (pregnancy sign or pregnancy bleeding) was $31 \cdot 5 \pm 0.7$ (S.E.) days. After conception, distinctive patterns were evident in the four parameters of most interest (Text-fig. 1).

Table 1. Details of the cycle of conception and the following pregnancy in rhesus monkeys relative to Day 0

\begin{tabular}{|c|c|c|c|c|c|c|c|c|c|}
\hline & \multicolumn{8}{|c|}{ Females } & \multirow[b]{2}{*}{ Mean \pm S.E. } \\
\hline & $55 \dagger$ & $68 \dagger$ & $1089 \dagger$ & $1126 \dagger$ & $1415^{*}$ & $1434 \dagger$ & $1506 \dagger$ & $1515^{*}$ & \\
\hline $\begin{array}{l}\text { Onset of menstruation } \\
\text { (Day) }\end{array}$ & -13 & -11 & -10 & -12 & -15 & -12 & -12 & -11 & $-12 \cdot 0 \pm 1 \cdot 5$ \\
\hline $\begin{array}{l}\text { Duration of menses } \\
\quad \text { (days) }\end{array}$ & 3 & 2 & 2 & 3 & 4 & 3 & 3 & 2 & $2 \cdot 8 \pm 0 \cdot 2$ \\
\hline $\begin{array}{l}\text { Onset of placental sign } \\
\text { (Day) }\end{array}$ & 17 & 20 & 25 & 20 & 16 & 17 & 22 & 19 & $19 \cdot 5 \pm 1 \cdot 1$ \\
\hline $\begin{array}{l}\text { Duration of placental } \\
\text { sign (days) }\end{array}$ & 11 & 11 & 8 & 11 & 25 & 14 & 10 & 9 & $12 \cdot 4 \pm 1 \cdot 9$ \\
\hline Parturition (Day) & 168 & 168 & 170 & 163 & 163 & 167 & $(98)$ & 167 & $166 \cdot 6 \pm 1 \cdot 0$ \\
\hline Sex and status of infant & Live +9 & Live $q$ & Live $?$ & Live + & Live +9 & $\begin{array}{l}\text { Still- } \\
\text { born } ठ\end{array}$ & Abortus & Live ơ & \\
\hline
\end{tabular}

* Day $0=2$ days before colour breakdown.

$\dagger$ Day $0=$ day of preovulatory oestradiol peak.

All six pairs for which behavioural data were collected showed two distinct and circumscribed periods of mating (Text-fig. 1b). The number of tests with ejaculation was greatest coincident with Day 0 and then declined rapidly, remaining at a low level until the 5th week of pregnancy, when males stopped ejaculating. All pairs thereafter experienced a 1-7 week interval during which no ejaculation occurred. With each pair, a second period of increased sexual activity then occurred, as indicated by ejaculations. Although the length of this second period of activity depended on the pair, the mid-points of the individual periods were similar for all pairs, ranging from Day 48 to Day 63 of pregnancy. Ejaculations ceased in all six pairs by the 17 th week of pregnancy and no ejaculations occurred throughout the rest of pregnancy or during the week after parturition. 

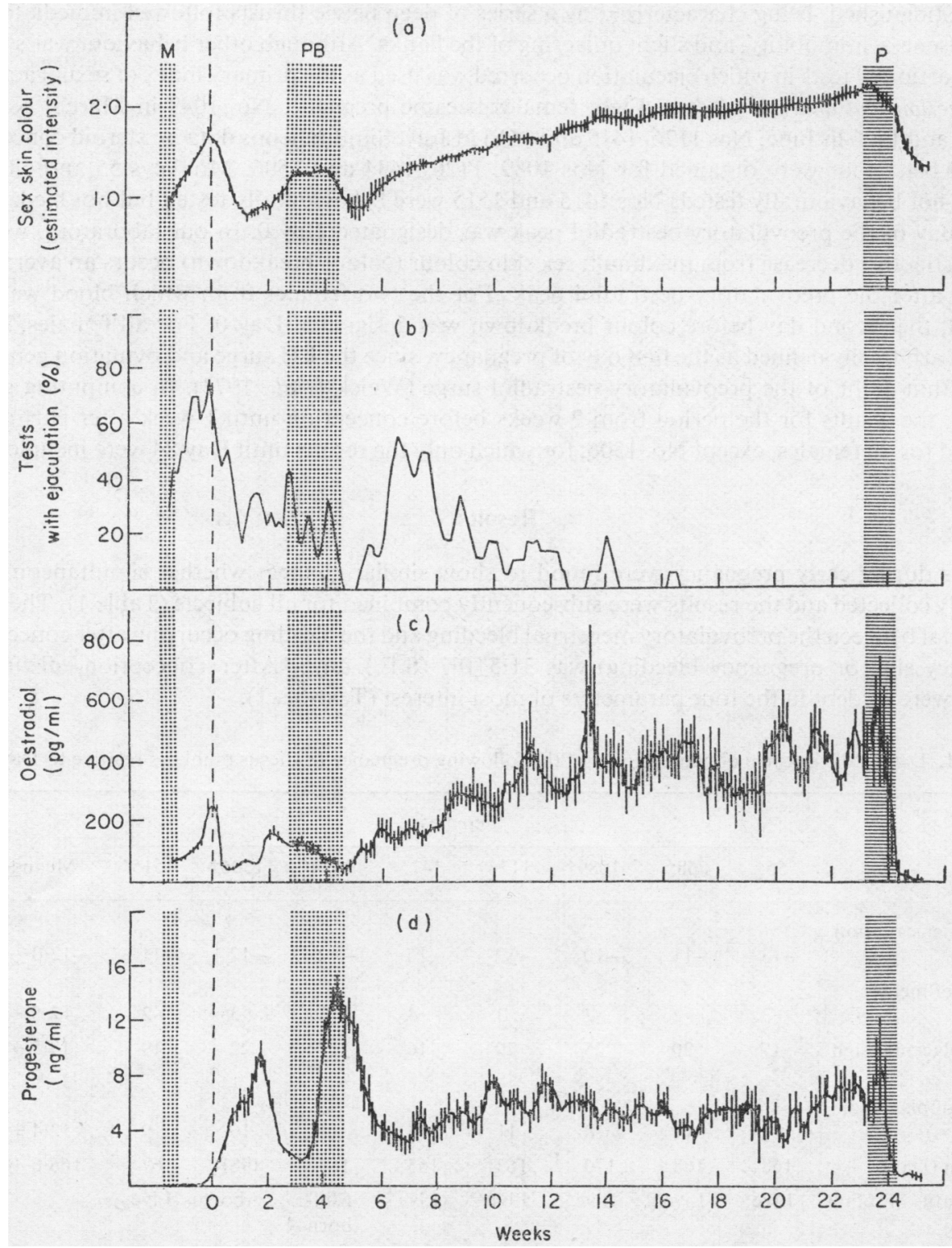

Text-fig. 1. The changes of (a) sex skin colour; (b) proportion of mating tests with ejaculations; (c) oestradiol concentrations; and (d) progesterone levels in pregnant rhesus monkeys. All the results are plotted as 3-day running means relative to the day of the preovulatory oestradiol peak (Day 0). Vertical bars represent the S.E.M. (a) Subjects, $N=8$; determinations, $n=1344$; (b) $N=6, n=1030$; (c) $N=6$, $n=435 ;$ (d) $N=6, n=435$. $M=$ menstruation of conception; $P B=$ pregnancy bleeding; $P=$ parturition.

The preovulatory oestradiol peak $(358 \pm 49 \mathrm{pg} / \mathrm{ml})$ appears attenuated in Text-fig. 1(c) because of its representation as part of a 3-day running mean. After some minor fluctuations, oestradiol levels increased during early pregnancy and remained at elevated levels for the last half of pregnancy. The overall pattern for oestradiol was mirrored by changes in female sex skin colour (Text-fig. 1a). Progesterone concentrations were of a different pattern, with two marked peaks on approximately Days 12 and 30. During the last half of pregnancy, progesterone continued at levels commonly found during the mid-luteal phase of ovulatory menstrual cycles without conception. 


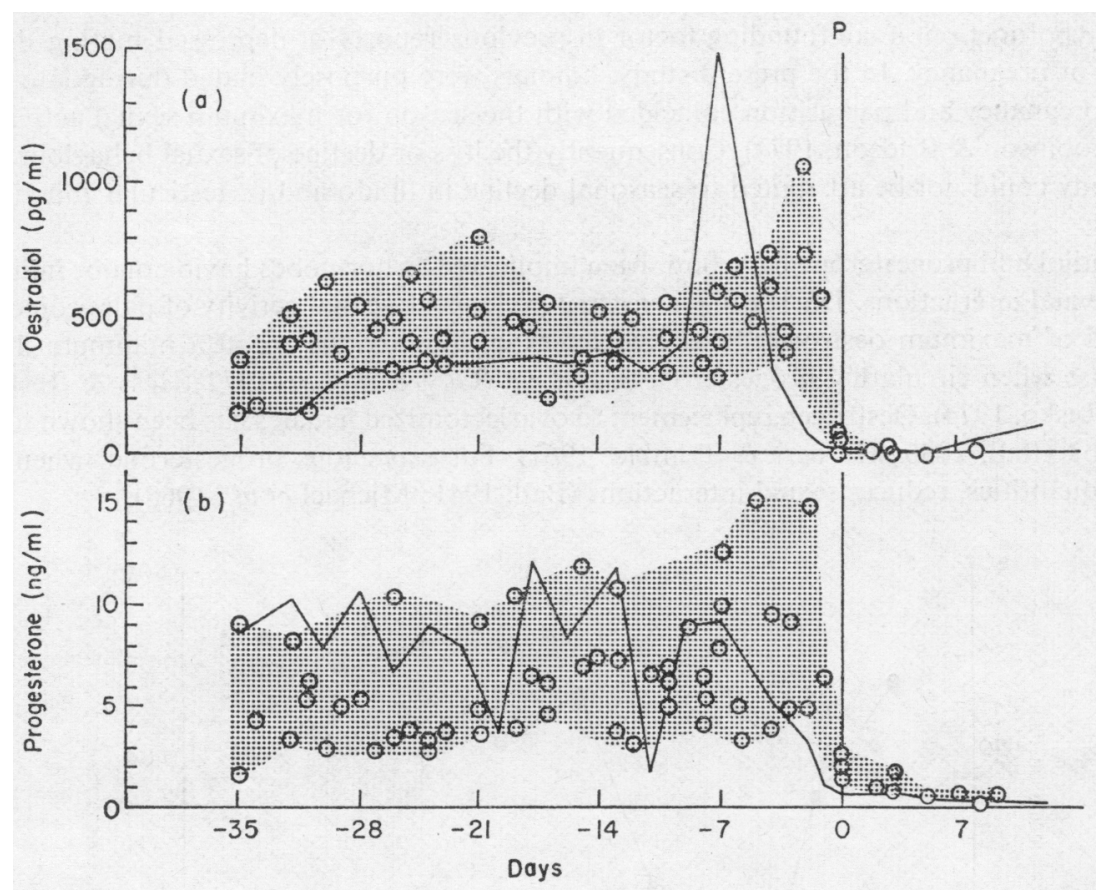

Text-fig. 2. Circulating levels of immunoreactive (a) oestradiol and (b) progesterone during the last weeks of pregnancy in rhesus monkey females. Individual circles represent determinations from five females giving birth at term (P). The continuous line represents data from a female (No. 1506) who aborted prematurely.

Titres of oestradiol and progesterone fell at parturition. Although the exact time of these changes relative to the onset of parturition is not known, Text-fig. 2 shows that the levels of oestradiol and progesterone were high before parturition and low on the day of and days following parturition. It can also be seen in this figure that the female who aborted has a pronounced oestradiol surge followed by relatively low oestradiol and progesterone values before abortion.

\section{Discussion}

Although some field workers have failed to detect post-conceptional sexual activity in the rhesus monkey (Altmann, 1962), it has been documented by others (Conaway \& Koford, 1964; Kaufmann, 1965; Loy, 1971). In contrast to our observations, Loy (1971) reported repeated cycles of sexual activity throughout pregnancy. However, his behavioural criteria included a number of activities, such as grooming, which cannot be considered sexual per se. When his data are re-examined with more stringent criteria, the results appear more similar to the laboratory findings; $85 \%$ of the pregnant females received series mounting or exhibited an ejaculatory plug between the 6th and 12th weeks of pregnancy, but none did so between the 12th week and parturition. Previous laboratory studies on rhesus sexual activity during pregnancy provide only sketchy data. Ball (1937) found no increases in female sexual invitations to male partners in the one rhesus female followed to term. In contrast, a female tested by Zumpe \& Michael (1970) displayed definite increases in the frequency of certain sexual solicitation gestures at approximately the same stage of pregnancy at which we observed increases in ejaculation frequency.

The existing information on rhesus mating in later pregnancy consistently indicates reduced sexual activity. However, rhesus monkeys experience seasonal changes in sexual activity and gonadal function under free-ranging conditions (Sade, 1964; Conaway \& Sade, 1965) and, to a lesser extent, in the laboratory (Robinson \& Bridson, 1974). Pregnancy normally extends into this period of 
gonadal hypofunction, a confounding factor in previous reports of depressed mating during the later part of pregnancy. In the present study, animals were purposely mated during late spring so that late pregnancy and parturition coincided with the season for maximum sexual activity in this colony (Robinson \& Bridson, 1974). Consequently the loss or decline of sexual behaviour observed in this study could not be attributed to seasonal decline in libido and/or testicular function of the males.

Oestradiol and progesterone have both been implicated as hormones having major influences on primate sexual interactions. During the menstrual cycle, peak sexual activity of pairs coincides with the period of maximum oestrogen levels, while sexual interactions are at a minimum during the luteal phase when circulating progesterone is highest (Goy \& Resko, 1972; Hess \& Resko, 1973; Eaton \& Resko, 1974). Oestrogen replacement to ovariectomized females has been shown to increase pair mating (Ball, 1936; Herbert \& Trimble, 1967), but exogenous progesterone, when given in sufficient quantities, reduces sexual interactions (Ball, 1941; Michael et al., 1968).

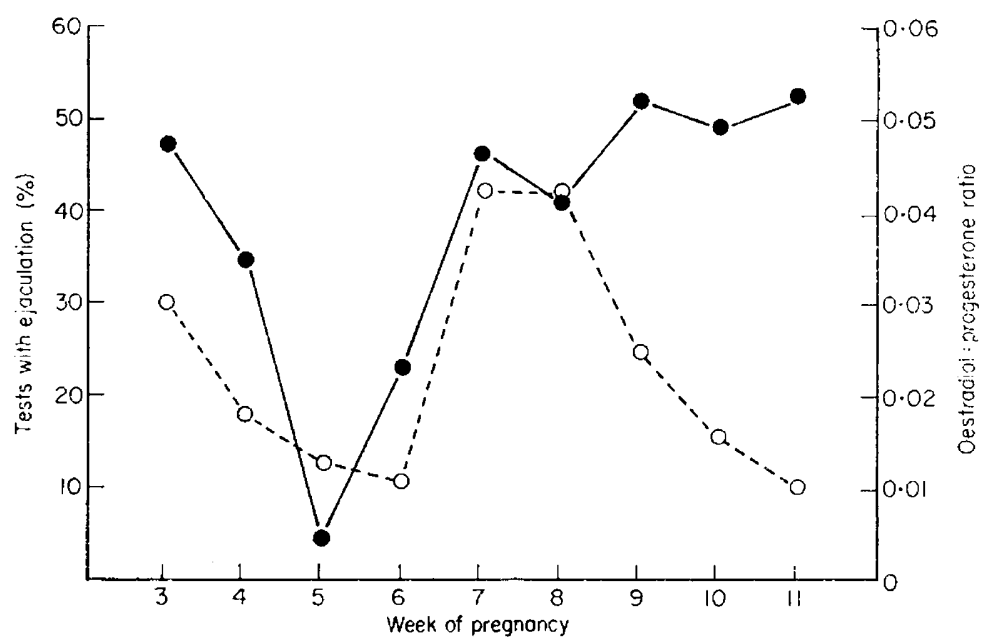

Text-fig. 3. The oestradiol:progesterone ratio (-) during the early weeks of pregnancy compared to ejaculation frequency $(0)$ in rhesus monkeys.

Our measurements of oestradiol and progesterone levels during pregnancy are consistent with those previously reported (Neill et al., 1969; Hodgen et al., 1972; Bosu et al., 1973). Both of these hormones are produced by the ovary and the placenta, and the marked fluctuations in their concentrations during early pregnancy might have an influence on the levels of sexual activity at that time. Comparison of sexual activity during early pregnancy to the oestradiol:progesterone ratio indicates that the positive correlation found between these factors during the menstrual cycle does continue into pregnancy, but only for a limited time. It can be seen in Text-fig. 3 that the \% of tests with ejaculation and the oestradiol:progesterone ratio follow a similar course only until the 8th week of pregnancy.

It appears that the levels of oestradiol during pregnancy, although as high as those of the preovulatory peak, are insufficient to maintain mating behaviour despite the fact that levels of progesterone at that time are no higher than those normally seen during an average luteal phase. It may be that the prolonged exposure to these progesterone levels during pregnancy has a greater effect than the more limited exposure associated with menstrual cycles. Prolonged progesterone exposure has been reported to antagonize the display of rhesus sexual activity (Ball, 1941; Michael et al., 1968), but there is some question as to the physiological significance of these results, given the finding that small doses of progesterone that are ineffective in significantly reducing sexual interactions should produce circulating levels at least as high or higher than those normally recorded during the luteal phase or pregnancy (Michael et al., 1968; Neill et al., 1969; Dierschke et al., 1973). 
Since pregnancy involves major endocrine and metabolic shifts, there are many additional factors which may influence primate sexual behaviour during gestation, either by their direct actions or through interaction with steroid hormones. The assay techniques we used do not distinguish between free and bound forms of the hormone, and hormone binding in women is known to change significantly during pregnancy (Vermeulen et al., 1969; Corval et al., 1971; Forest et al., 1971). Despite the apparent constant high oestrogen levels in pregnant rhesus monkeys, there may be a reduction in the availability of the hormone during late pregnancy, although the intensity of the sex skin colour indicates a continued effectiveness of the hormone, at least at certain peripheral sites. Another possibility is that oestrogen has a biphasic action on mating behaviour of primates. Michael et al. (1967) reported that graded increases in the dose of oestradiol to an ovariectomized female rhesus monkey produce differential changes in the behaviour of the male partner and the interaction of the pair. The male's sexual performance was stimulated by lower doses but there was a progressive suppression with higher doses of oestradiol. Thus, the prolonged exposure to elevated oestrogen titres during pregnancy may in itself eventually reduce sexual activity.

Testosterone also affects rhesus sexual interactions, but it presumably influences the display of particular female responses more than the criteria we used to assess mating (Herbert \& Trimble, 1967; Trimble \& Herbert, 1968). Knowledge of testosterone levels might be helpful to evaluate its possible influence on post-conceptional mating, although questions remain as to whether testosterone effects in the female primate are mediated directly, by conversion to oestrogens, or by competition in certain oestrogen-binding systems (Ryan et al., 1972). Since most fetuses in this study were female, fetal testosterone can be considered an unlikely cause of the behavioural effects observed in the mothers.

Our observations do not permit us to isolate the particular factors regulating the observed fluctuations in primate sexual behaviour after conception, but they do indicate that sexual activity at this time is not independent of hormonal or reproductive condition. The presence of behaviourally significant changes in oestrogen and progesterone during pregnancy is further supported by recent reports on primate feeding behaviour. As with sex behaviour patterns, levels of food intake show cyclic changes during the menstrual cycle and are influenced by gonadal hormones (Czaja \& Goy, 1975). The pattern of changes of feeding of rhesus monkeys during pregnancy (Czaja, 1975) appears very similar to the patterns reported here for sexual activity.

This work was supported by grant RR-00167 from the National Institutes of Health to the Wisconsin Regional Primate Research Center and grant MH-21312 from the National Institutes of Mental Health. Special thanks are given to Ms Arlene Mitchell and Ms Karen Brookhyser for laboratory assistance, to the Wisconsin Primate Center Breeding Colony staff for observation time and data collection, and to Ms Elizabeth Shirah for her expert typing and manuscript preparation. The specific progesterone antibody was generously provided by $\mathrm{Dr} J$. A. Resko. The oestrogen antibody was purchased from Mr Donald Begley, Holly Hill Farms, Hillsboro, Oregon. This article is Publication No. 15-010 of the Wisconsin Regional Primate Research Center.

\section{References}

ALLEN, E. (1927) The menstrual cycle in the monkey Macacus rhesus: observation on normal animals, the effects of removal of the ovaries and the effects of injections of ovarian and placental extracts into the spayed animal. Contrib. Embryol. 19, 1-43.

AltmanN, S.A. (1962) A field study of the sociobiology of rhesus monkeys, Macaca mulatta. Ann. N.Y. Acad. Sci. 102, 338-435.

BALL, J. (1936) Sexual responsiveness in female monkeys after castration and subsequent estrin administration. Psychol. Bull. 33, 811.

BALL, J. (1937) Sexual responsiveness and temporarily related physiological events during pregnancy in the rhesus monkey. Anat. Rec. 67, 507-512.

BALl, J. (1941) Effect of progesterone upon sexual excitability in the female monkey. Psychol. Bull. 38, 533.

Ball, J. \& Hartman, C.G. (1935) Sexual excitability as related to the menstrual cycle in the monkey. Am. J. Obstet. Gynec. 29, 117-119.

BielerT, C.F. \& GoY, R.W. (1973) Sexual behavior of male rhesus: effects of repeated ejaculation and partner's cycle stage. Horm. \& Behav. 4, 109122. 
Bosu, W.T.K., Johansson, E.D.B. \& Gemzell, C. (1973) Peripheral levels of oestrogens, progesterone and 17 $\alpha$-hydroxyprogesterone during gestation in the rhesus monkey. Acta endocr., Copenh. 74, 348-360.

Bullock, D.W., Paris, C.A. \& Goy, R.W. (1972) Sexual behaviour, swelling of the sex skin, and plasma progesterone in the pigtail macaque. J. Reprod. Fert. 31, 225-236.

CARPEnTER, C.R. (1942) Sexual behavior of free ranging rhesus monkeys (Macaca mulatta). I. Specimens, procedures, and behavioral characteristics of estrus. II. Periodicity of estrus, homosexuality, autoerotic and non-conformist behavior. J. comp. Psychol. 33, $113-142 ; 143-162$.

Conaway, C.H. \& Koford, C.B. (1964) Estrous cycles and mating behavior in a free-ranging band of rhesus monkeys. J. Mammal. 45, 577-588.

Conaway, C.H. \& SADE, D.S. (1965) The seasonal spermatogenic cycle in free ranging rhesus monkeys. Folia primatol. 3, 1-12.

Corval, P.L., Chrambach, A., Rodbard, D. \& BARDIN, C.W. (1971) Physical properties and binding capacity of testosterone-estradiol-binding globulin in human plasma, determined by polyacrylamide gel electrophoresis. J. biol. Chem. 246, 3435-3443.

CzajA, J.A. (1975) Food rejection by female rhesus monkeys during the menstrual cycle and early pregnancy. Physiol. Behav. 14, 579-587.

CzAja, J.A. \& Bielert, C. (1975) Female rhesus sexual behavior and distance to a male partner: relation to stage of the menstrual cycle. Arch. sex. Behav. 4, 583-597.

CzAJA, J.A. \& GoY, R.W. (1975) Ovarian hormones and food intake in guinea pigs and rhesus monkeys. Horm. \& Behav. (in press)

CzaJA, J.A., Eisele, S.G. \& GoY, R.W. (1975) Cyclical changes in the sexual skin of female rhesus: relationships to mating behavior and successful artificial insemination. Fedn Proc. Fedn Am. Socs exp. Biol. 34, 1680-1684.

Dirrschke, D.J., Yamaji, T., Karsch, F.J., Weick, R.F., Weiss, G. \& KNonIL, E. (1973) Blockade by progesterone of estrogen-induced $\mathrm{LH}$ and FSH release in the rhesus monkey. Endocrinology 92, 1496-1501.

EAtoN, G.G. \& Resko, J.A. (1974) Ovarian hormones and sexual behavior in Macaca nemestrina. J. comp. Physiol. Psychol. 86, 919-925.

Eaton, G.G., Slob, A. \& Resko, J.A. (1973) Cycles of mating behaviour, oestrogen and progesterone in the thick-tailed bushbaby (Galago crassicaudatus crassicaudatus) under laboratory conditions. Anim. Behav. 21, 309-315.

EkINs, R. \& Newman, B. (1970) Theoretical aspects of saturation analysis. In Steroid Assay by Protein Binding, pp. 11-30. Eds E. Diczfalusy \& A. Diczfalusy. Bogtrykkeriet Forum, Copenhagen.

Evans, C.S. \& GoY, R.W. (1968) Social behaviour and reproductive cycles in captive ring-tailed lemurs (Lemur catta). J. Zool., Lond. 156, 181-197.

Falicov, C.J. (1973) Sexual adjustment during first pregnancy and postpartum. Am. J. Obstet. Gynec. 117, 991-1000.
Forest, M.G., AnCes, I.G., TAPPer, A.J. \& Migeon, C.J. (1971) Percentage binding of testosterone, androstenedione and dihydroisoandrosterone in plasma at the time of delivery.J. clin. Endocr. Metab. $32,417-425$.

GoldFoot, D.A. (1971) Hormonal and social determinants of sexual behavior in the pigtail monkey (Macaca nemestrina). In Normal and Abnormal Development of Brain and Behavior, pp. 325-341. Eds G. B. A. Stoelinga \& J. J. van der Werff ten Bosch. Leiden Press, Leiden.

GoY, R.W. \& RESKo, J.A. (1972) Gonadal hormones and behavior of normal and pseudohermaphroditic nonhuman female primates. Recent Prog. Horm. Res. 28, 707-733.

Hanby, J.P., Robertson, L.T. \& Phoenix, C.H. (1971) The sexual behaviour of a confined troop of Japanese macaques. Folia primatol. 3, 22-49.

Hartman, C.G. (1932) Studies in the reproduction of the monkey Macacus (Pithecus) rhesus, with special reference to menstruation and pregnancy. Contrib. Embryol. 23, 1-161.

Herbert, J. \& Trimble, M.R. (1967) Effect of oestradiol and testosterone on the sexual receptivity and attractiveness of the female rhesus monkey. Nature, Lond. 216, 165-166.

Hess, D.L. \& Resko, J.A. (1973) The effects of progesterone on the patterns of testosterone and estradiol concentrations in the systemic plasma of the female rhesus monkey during the intermenstrual period. Endocrinology 92, 446-453.

Hess, J.P. (1973) Some observations on the sexual behaviour of captive lowland gorillas. In Comparative Ecology and Behaviour of Primates, pp. 508581. Eds R. P. Michael \& J. H. Crook. Academic Press, New York.

Hodgen, G.P., Dufau, M.L., Cart, K.J. \& Tullner, W.W. (1972) Estrogens, progesterone and chorionic gonadotropin in pregnant rhesus monkeys. Endocrinology 91, 896-900.

Hotchkiss, J., Atkinson, L.E. \& KnOBIL, E. (1971) Time course of serum estrogen and luteinizing hormone (LH) concentrations during the menstrual cycle of the rhesus monkey. Endocrinology 89 , 177-183.

Johansson, E.D.B. (1969) Progesterone levels in peripheral plasma during the luteal phase of the normal human menstrual cycle measured by a rapid competitive protein binding technique. Acta endocr. Copenh. 61, 592-606.

Johansson, E.D.B., Neill, J.D. \& KNobil, E. (1968) Periovulatory progesterone concentration in the peripheral plasma of the rhesus monkey with a methodological note on the detection of ovulation. Endocrinology 82, 143-148.

KaUfMaNN, J.H. (1965) A 3-year study of mating behaviour in a free-ranging band of monkeys. Ecology 46, 500-512.

KENNY, J.A. (1973) Sexuality of pregnant and breast feeding women. Arch. sex. Behav. 2, 215-229.

LindBerg, D.G. (1971) The rhesus monkey in north India: an ecological and behavioural study. In Primate Behavior: Developments in Field and 
Laboratory Research, Vol. 2, pp. 1-106. Ed. L. A. Rosenblum. Academic Press, New York.

LISK, R.D. (1973) Hormonal regulation of sexual behavior in polyestrous mammals common to the laboratory. In Handbook of Physiology, Section 7: Endocrinology, Vol. II, pp. 223-260. Ed. R. O. Greep. Williams \& Wilkins, Baltimore.

LoY, J. (1971) Estrous behavior of free-ranging rhesus monkeys (Macaca mulatta). Primates 12, 1-31.

MASTERS, W.H. \& JoHNSON, V.E. (1966) Human Sexual Response. Little, Brown \& Co., Boston.

Michael, R.P. \& Herbert, J. (1963) Menstrual cycle influences, grooming behaviour, and sexual behaviour in the rhesus monkey. Science, $N, Y, 140,500-501$.

Michael, R.P., Herbert, J. \& Welegalla, J. (1967) Ovarian hormones and the sexual behaviour of the male rhesus monkey (Macaca mulatta). $J$. Endocr. 39, 81-98.

Michael, R.P., SaAYMan, G. \& Zumpe, D. (1968) The suppression of mounting behaviour and ejaculation in male rhesus monkeys (Macaca mulatta) by administering progesterone to their female partners. J. Endocr. 41, 421-431.

Neill, J.D., Johansson, E.D.B. \& Knobil, E. (1969) Patterns of circulating progesterone concentrations during the fertile menstrual cycle and the remainder of gestation in the rhesus monkey. Endocrinology 84, 45-48.

NuTI, L.C., MCShaN, W.H. \& MEYer, R.K. (1974) Effect of ovine FSH and $\mathrm{LH}$ on serum steroids and ovulation in hypophysectomized immature female rats. Endocrinology 95, 682-689.

REsko, J.A. (1971) Sex steroids in adrenal effluent plasma of the ovariectomized rhesus monkey. $J$. clin. Endocr. Metab. 33, 940-948.

Resko, J.A., Norman, R.L., Niswender, G.D. \& SPIES, H.G. (1974) The relationship between progestins and gonadotropins during the late luteal phase of the menstrual cycle in rhesus monkeys. Endocrinology 94, 128-135.

Robinson, J.A. \& BRIDSON, W.E. (1974) Sexual behavior and plasma androgen concentration in laboratoryhoused rhesus males: effects of age and season. Proc. 7th A. Meeting, Soc. Study Reprod. Ottawa, Abstr. No. 75.

Rowell, T.E. (1972) Female reproduction cycles and social behavior in primates. Adv. Stud. Behav. 4, 69-105.
Ryan, K.J., Naftolin, F., Reddy, V., Flores, F. \& Petro, Z. (1972) Estrogen formation in the brain. Am. J. Obstet. Gynec. 114, 454-460.

SADE, D.S. (1964) Seasonal cycle in size of testes of free-ranging Macaca mulatta. Folia primatol. 2, 171-180.

SCRUTON, D.M. \& HERBERT, J. (1970) The menstrual cycle and its effect on behaviour in the Talapoin monkey (Miopithecus talapoin). J. Zool., Lond. 162, 419-436.

ThorneycrofT, I.H. \& Stone, S.C. (1972) Radioimmunoassay of serum progesterone in women receiving oral contraceptive steroids. Contraception 5, 129-146.

Trimble, M.R. \& Herbert, J. (1968) The effect of testosterone or oestradiol upon the sexual and associated behaviour of the adult female rhesus monkey. J. Endocr. 42, 171-185.

UDRY, J.R. \& MORRIs, N.R. (1968) Distribution of coitus in the menstrual cycle. Nature, Lond. 220, 593-596.

VAN DER MOLEN, H.J. (1970) Estimation of androstenedione and testosterone by physico-chemical methods. In The Androgens of the Testis, p. 145. Ed. K. B. Eik-Nes. Marcel Dekker, Inc., New York.

VAN LAWICK-Goodall, J. (1969) The behaviour of free-living chimpanzees in the Gombe Stream Reserve. Anim. Behav. Mongr. 1, 165-311.

Vermeulen, A., Verdonck, L., Van der Straeten, M. \& ORIE, N. (1969) Capacity of the testosteronebinding globulin in human plasma and influences of specific binding of testosterone on its metabolic clearance rate. J. clin. Endocr. Metab. 29, 14701480.

WeICK, R.F., DIERSCHKe, D.J., KARSCh, F.J., BUTLER, W.R., Нотchkiss, J. \& KNoBlL, E. (1973) Periovulatory time courses of circulating gonadotropic and ovarian hormones in the rhesus monkey. Endocrinology 93, 1140-1147.

Young, W.C. (1961) The hormones and mating behavior. In Sex and Internal Secretions, Vol. II, pp. 1173-1239. Ed. W. C. Young. Williams \& Wilkins, Baltimore.

ZUMPE, D. \& MiChAEL, R.P. (1970) Ovarian hormones and female sexual invitations in captive rhesus monkeys (Macaca mulatta). Anim. Behav. 18, 293-301. 